\title{
SANTIAGO POZNANSKY
}

\author{
UNIVERSIDAD DE BUENOS AIRES
}

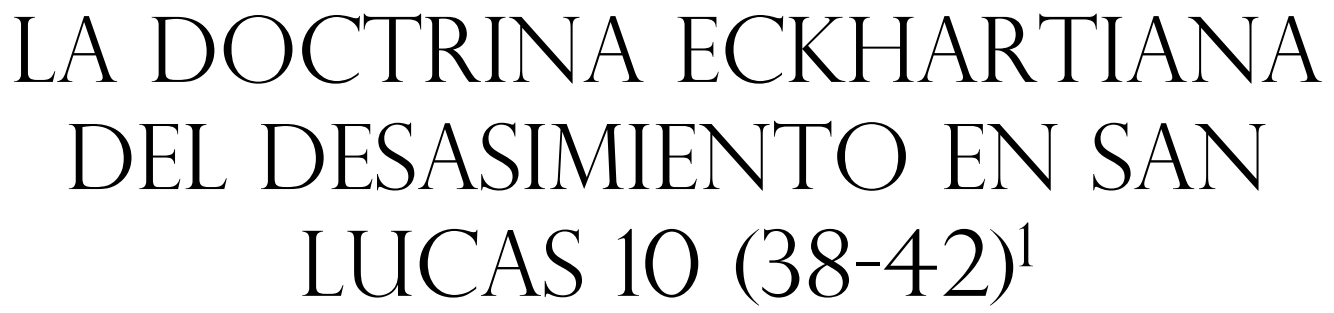

THE ECKHARTIAN DOCTRINE OF DETACHMENT IN SAINT LUKE 10 (38-42)

poznansky.santiago@gmail.com

Aceptación: 25/11/2020

Recepción: 29/01/2021

\section{RESUMEN}

El evangelio de San Lucas revela la visita de Jesús al hogar de Marta y María. Eckhart en su sermón 86 reivindica a Marta sobre su hermana María rebelándose así a la tradicional reivindicación de la contemplación por sobre la acción. Responderá Eckhart al reivindicar a Marta que esa vida digna es la vida donde nuestras almas son unas con Dios in vía. En una primera parte expondré la doctrina eckhartiana del desasimiento. En una segunda parte expondré la reivindicación de Marta en la lectura eckhartiana del evangelio y finalmente mostraré que se debe a que ella logra el ideal de unión mística que propone la doctrina eckhartiana del desasimiento.

\section{PALABRAS CLAVE}

Acción, contemplación, Evangelio de San Lucas, mística.

\section{ABSTRACT}

The Gospel of Saint Luke reveals Jesus' visit Martha and Mary 's home. In his sermon number 86 Eckhart vindicates Marta over her sister Mary, rebelling himself against the traditional claim of contemplation over action. Eckhart says that Marta's dignified life is the life where our souls are one with God in via. In the first part I will explain the Eckhartian detachment doctrine. In a second part I will expose Marta's vindication in the Eckhartian reading of the Gospel and show that it is possible because she lives according to the detachment doctrine.

\section{KEY WORDS}

Action, contemplation, Saint Luke's Gospel, mysticism.

\footnotetext{
${ }^{1}$ Agradezco al Dr. Ezequiel Ludueña por sus valiosísimos comentarios a los borradores del presente texto y por haberme introducido en el pensamiento místico de Meister Eckhart.
}

Tábano, no. 17 (2021), 45-55.

DOI: https://doi.org/10.46553/tab.17.2021.p45-55 


\section{INTRODUCCIÓN}

El Maestro Eckhart fue un maestro de vida y un maestro de teología. Es en su obra en lengua vernácula donde despliega su doctrina del desasimiento, que es la puerta de entrada a la unión mística del alma del humano con Dios. El humano que actúa sin perturbarse, sin apegarse y sin orientar su acción a nada, logrará dicha perfección espiritual. La mística eckhartiana se centrará en dar cuenta de qué manera Dios está presente en las acciones que realizamos habitualmente. ${ }^{2}$

Sobre la controversia exegética en torno al misticismo de Eckhart, Milem sostiene: "Su obra latina apuntaba estudiantes de teología mientras que su prédica en alemán a monjas y beguinas, así como a interesados en la experiencia mística" (Milem, 2012, p. 342). Albert se refiere a dicha cuestión como una cuestión abierta para la historia del pensamiento eckhartiano: "es precisamente la tarea de la investigación en historia de la filosofía el responder si el teólogo y fraile dominico debe ser comprendido desde una perspectiva mística o de una filosófica" (Albert, 2012, pp. 723-726).

En su plática sexta Eckhart introduce a su auditorio su doctrina del desasimiento para que así conozcan el camino que debe seguir quien aspira a la unión con Dios: "Debe aprender a penetrar a través de las cosas y aprehender a su Dios ahí dentro, y a ser capaz de imprimir su imagen (la de Dios) en su fuero íntimo, vigorosamente, de manera esencial" (Eckhart, 2013, p. 68). Podemos notar aquí que el deber del desasido es excelso y que quien no sabe vivir enfoca su intelecto a las cosas, vive apegado a ellas y no logra penetrar a través de ellas. ${ }^{3}$ Sucede que si buscáramos unirnos a Dios pensándolo en nuestras acciones o pensando su esencia, aunque esto fuera posible, sería perjudicial puesto que desvanecido el pensamiento se desvanece Dios de nosotros. El Dios que no se desvanece es aquél que está por encima de todo y aquél que no se desvanece. Si nos apartamos de él apegándonos al mundo jamás estaremos unidos a Dios.

\footnotetext{
${ }^{2}$ Milem (2012) releva los sentidos que da de desasimiento Eckhart distinguiendo entre cinco. 1) el desasimiento y desapego de las cosas ordinarias y actuar "sin por qué" como una práctica espiritual. Olvidar deseos y metas y aun así seguir actuando. Bajo este esquema la unión mística depende de acciones humanas en el tiempo y cuan desapegadas son de "esto y aquello", renunciar a las cosas ordinarias y apegos como expresa el maestro en su sermón 2. 2) La presencia de Dios en el intelecto, esa potencia del alma con la que alcanzamos la verdad. En este esquema la unión con Dios pareciera ser más bien eterna y no temporal. 3)La presencia de Dios puede calificarse como más íntima. A colación de ello Milem retoma el "castillo del alma" del Sermón 2 el cual es distinguido de esa potencia del alma que es el intelecto. 4) Este esquema versa sobre la ontología apofática eckhartiana y los trascendentales. Las creaturas son pura nada y por el sólo hecho de existir están unidas con Dios, 5) El Maestro arma un modelo de unión místico basado en el obrar como por ejemplo el Sermón 6 cuando sostiene que si el carpintero no trabaja la casa no se erige

${ }^{3}$ En el corpus eckhartiano se incluye un tratado titulado Del desasimiento. No lo trabajaré ya que es ampliamente reconocido por los especialistas como un escrito apócrifo.
} 
Esa falta de perturbación y de apego con lo que hay a nuestro alrededor es la condición para caracterizar a alguien como un "espíritu libre". El alma que no se apega a nada no es esclava de nada. Puede darse el caso de no poseer y aun así anhelar lo que no se posee. En ese caso no nos estamos desapegando de las cosas aunque no las poseamos materialmente. ${ }^{4}$

Ese ideal de libertad espiritual, de aquel que se desapega de tal manera de las cosas y de las preocupaciones, es un ideal que tiene su antagónico. De allí que en su plática tercera Eckhart diserte sobre aquellos que no se desapegaron y por tanto están llenos de su propia voluntad y no se vaciaron para que penetre en ellos la voluntad divina. Eckhart es tajante con aquel que no liberó su espíritu: "quien te perturba eres tu mismo a través de las cosas, porque te comportas desordenadamente frente a ella" (Eckhart, 2013, p. 65). La vida digna de ser vivida no es entonces la suspensión de la acción como la de aquellos que adoptan la ermitaña o ascética sino que quien sabe vivir no se aleja de las cosas sino que penetra a través de ellas. ${ }^{5}$

Según Eckhart la espiritualidad correcta consiste en renunciar a nosotros mismos y allí también habremos renunciado a todas las cosas. Es crucial notar que el Maestro no expone sin más que debemos renunciar a las cosas sino que antecede a ello una prescripción espiritual donde primero debemos renunciar a nosotros mismos. Eckhart sostiene al respecto: "El hombre que dejara un reino o todo el mundo y se quedará consigo mismo, no habría renunciado a nada [...], quien renuncia a su voluntad y a sí mismo ha renunciado tan efectivamente a todas las cosas como si hubieran sido de su libre propiedad y él las hubiese poseído con pleno poder" (Eckhart, 2013, p. 66). El abandono físico o la desposesión material no son significativas si no abandonamos desde nuestro interior las cosas y renunciamos también a nosotros mismos.

Quien es pobre de espíritu no podrá apegar su alma a nada ya que no podremos ser instrumentos de Dios sin estar vacíos. Es quien evita llenarse de apego, de goce o de sufrimiento quien se vacía. Eckhart utiliza la siguiente metáfora: "hasta donde sales de todas las cosas, hasta ahí, ni más ni menos, entra Dios con todo lo suyo, siempre y cuando en todas las cosas abandones completamente lo tuyo" (Eckhart, 2013, p. 66). Quien se desase es quien ya no se enfoca en esta o aquella cosa y ha borrado de su interior todo rastro de cosa alguna. Esa "aniquilación de la creaturidad" como la llama Eckhart (2013, p. 179) remite una vez más al hecho de desapegarnos de las cosas, desapegar nuestras acciones de sus resultados y expectativas y actuar sin por qué. Es tal el desapego del que

\footnotetext{
${ }^{4}$ Comenta Eckhart sobre la libertad de espíritu: "El ánimo libre no se perturba por nada, ni está atado a nada, ni tiene atado lo mejor de sí mismo a ningún modo" (Eckhart, 2013, p. 66)

${ }^{5}$ Sobre la cuestión de la posesión de las cosas Radler (2010) señala que respecto a las posesiones materiales Eckhart no sostiene ni la postura dominica (que no censuraba la posesión) ni la franciscana (que sí la censuraba) al respecto sino que su mística es una vía superadora de ambas posiciones.
} 
obra desasido que no espera nada de la acción. Esa estrecha relación entre el desasimiento y la "vida sin por qué" en la filosofía eckhartiana se da en que ambos son condiciones prácticas para que el ser humano pueda comprender cuál es la finalidad de su trabajo espiritual. Es dicho trabajo espiritual, el desapego, lo que nos lleva a la esencia de lo que debemos ser: una mismidad con Dios. ${ }^{6}$

Si bien quien se desase actúa sin por qué y desapegado de lo mundano no se sigue de esto que la mística eckhartiana no tenga una finalidad clara. En efecto lo tiene; ese punto cúlmine es la unión mística. Lograr el traspaso (durchbruch) y poder subsumir nuestras almas con la esencia de Dios a tal punto de que ambas se fundan en una y no haya ya distinción ontológica. Quien sigue la doctrina eckhartiana del desasimiento será uno con Dios. Si bien es claro que quien vive en el buen camino espiritual no espera ningún resultado inmediato de sus acciones diarias, el mismo Eckhart deja a entrever que quien vive correctamente obtendrá su recompensa in vía, y esa recompensa es divina y sublime: estar en unión in vía con Dios. ${ }^{7}$

Eckhart se hace de una metáfora para dar cuenta de la subsunción del alma en la esencia de Dios: los muros y las fronteras (Eckhart, 2013, p. 227). Si no existe separación entre yo y el muro estoy junto al muro pero no en el muro. Respecto a las cuestiones espirituales esto no es así. Quien se despegó, actuó desasido, se vació, realizó el traspaso y se subsumió en Dios es quien ha derribado todo muro y borrado toda frontera. El summum de quien está desasido es la indistinción ontológica entre su hombre interior y el Señor. ${ }^{8}$

\section{MARTA Y MARÍA EN EL SERMÓN 86}

Eckhart se encarga de estructurar la visita de Jesús al hogar de Marta y María (episodio que se halla en el Evangelio de San Lucas 10 (38-40) de modo que se establezcan claramente las oposiciones entre la acción y la contemplación. Por un lado Marta anda de aquí para allá y sirve al huésped ejecutando acciones hospitalarias mientras que por el otro María se recuesta y lo escucha. María también es servil, pero sirve mediante la inacción (está recostada) y la contemplación propia de la escucha.

\footnotetext{
${ }^{6}$ Schurmann expresa al respecto: "el Maestro Eckhart solo trata la última consecuencia del desapego o desprendimiento como la condición práctica para el entendimiento del ser. Abandonar las cosas, abandonar a Dios, vivir sin por qué" (Schurmann, 1997, p. 807).

${ }^{7}$ Una vez más huelga remarcar la naturaleza ontológica de la unión del ser humano con Dios. Como argumenta Duclow: "El ascenso final del alma va más allá de este conocimiento, ya que en varios textos Eckart describe un traspaso místico que va más allá de la unión intelectual del alma con el Hijo. Este traspaso nos transporta dentro del mismo Dios" (Duclow, 1989, p. 36. La traducción es mía)

${ }^{8}$ Ver Filippi, 2010, p. 66.
} 
Contra lo que se podría pensar (ya que se menciona en el sermón que era María quien se hallaba en un estado interno de felicidad y de un desbordante deseo) Eckhart comenta que la distraída Marta es la hermana que pareciera comprender la verdadera espiritualidad. La correcta vida espiritual es posible únicamente "cuando la cima más alta del alma no se inclina por causa de las alegrías, no se ahoga en el bienestar, sino que permanece poderosa sobre ellas" (Eckhart, 2013, p. 107). María por su parte está a los pies de Jesús contemplándolo y llenándose de él. María no actuaba sin por qué, sino que actuaba a fin de buscar el regocijo y bienestar de la verdad divina. Ella no actuaba renunciando a ella misma y abandonando las cosas que la rodeaban sino que buscaba apegarse con fervor a las palabras de Jesús.

Respecto a la desorientación y distracción de Marta en el Evangelio: ¿Cómo esa supuesta incorrección espiritual es en realidad lo correcto y la espiritualidad necesaria para que se dé el traspaso místico? Ella se perdía en las múltiples acciones sólo en apariencia, nunca dejó de orientarse hacia Dios y eso lo lograba "des-dirigiendo" su contemplación y preocupación de sus acciones. Ella actuaba, es cierto, pero actuaba sin por qué. Aquí está toda la dignidad de Marta. Ella no se perturbaba y era tal su "no-perturbación" que incluso parece que no comprende la magnitud del huésped que está recibiendo en su hogar.

El acompañamiento de la contemplación en la acción desasida es en términos pseudo paradójicos un "no acompañar". El desasimiento eckhartiano no es una forma de contemplación sino que es cómo vivimos las acciones que realizamos. Este es el trabajo espiritual que propone Eckhart y por eso critica en su Sermón 86 a María. Ésta se consagra a Dios en apariencia pero en realidad está perdida, estupefacta y llena de pasión por dentro. María renuncia al obrar y no trabaja por vaciarse o desapegarse, más bien se apega a las palabras de Jesús y se llena de regocijo hasta más no poder. Incluso físicamente no sólo suspende la acción sino que se sienta y recuesta a los pies de Jesús, señal de reposo por excelencia. Pero en la mística eckhartiana a Dios se lo encuentra en todas las obras al actuar desapegado de la acción misma y del resultado que la acción pueda acarrear.

Como se ha señalado en la introducción, la lectura de Eckhart no es la lectura tradicional del episodio bíblico. San Agustín y Santo Tomás, por ejemplo, encarnan la lectura tradicional del evangelio donde se valora a María por sobre Marta. Como se ha mostrado San Lucas en su Evangelio describe a una María cuyo alma se halla llenísima. Dicho status espiritual San Agustín y Santo Tomás lo elogiaron mientras que Eckhart lo reprobó. Aunque ni San Agustín ni Santo Tomás vituperan a Marta ya que actuar misericordiosamente y asistir al débil es cosa buena, pero no la mejor. ${ }^{9}$

9 En la lectura tradicional del Evangelio además de San Agustín se halla Santo Tomás. Comienza reconstruyendo argumentos que da Aristóteles en el libro X de la Ética Nicomaquea para sostener esa primacía, 
Lo que en la lectura tradicional del evangelio era digno de reproche (como la preocupación de Marta por servirlo a su huésped en vez de preocuparse por cosas más importantes como María) se invierte en la lectura eckhartiana. La ocupación de Marta en las múltiples acciones que despliega para recibir hospitalariamente a Jesús es para Eckhart una demostración de maestría espiritual. Argumenta Eckhart al respecto: "Marta era tan íntegra que su actuar no le afectaba: la obra y la acción la condujeron a la bienaventuranza eterna" (Eckhart, 2013, p. 110). Por eso respecto al doble llamado por su nombre por parte de Jesús a Marta Eckhart se encarga de resaltar que no es un reproche o censura como se sostiene en la lectura tradicional sino que es una reivindicación ya que pocos son llamados por su nombre por parte de Dios y menos que menos dos veces. Retomando a Isidoro, Eckhart señala que la primera vez que Cristo llama a Marta por su nombre es para indicar cierta perfección y la segunda vez indica que ella tenía todo lo que se puede pedir en esta vida (Eckhart, 2013, p. 105).

María es censurada por Eckhart, ya que no se ocupa de ejercitar un provecho espiritual sino que la orienta el placer. Las últimas líneas del Sermón enfatizan la fe que el Señor tiene en María para que acabe siendo como es Marta y el propio Eckhart pronuncia que María llegaría a ser tal como Marta deseaba. Ahora bien, ¿qué le encuentra Eckhart digno de admiración espiritual a esa mujer que distraída y torpe se empeña por servirle una taza de alguna bebida a Jesús en vez de contemplarlo y estar próximo a él? Eckhart, como se ha mencionado, introduce la figura de Marta haciendo notar que tenía el fondo de su

menta a dos pares de hermanas. Además de Raquel y Lía (esposas de Jacob), Tomás habla de Marta y María, y su relación con la acción y la contemplación. La vida contemplativa es más continua: María se mantiene tumbada a los pies de Jesús mientras que Marta acaba una acción liviana para comenzar con otra. La vida contemplativa es más placentera: mientras María se deleitaba Marta se turbaba. La vida contemplativa favorece más el abastecerse a uno mismo: Marta estaba preocupada por muchas cosas. La vida activa se dedica a lo divino mientras que la activa a lo mundano: María contemplaba (Tomás dice oía) al verbo mientras que Marta servía al verbo encarnado. Tomás agrega un argumento no aristotélico sino divino que el Señor expresa en el Evangelio: María eligió la mejor parte, la que jamás le será quitada (Tomás de Aquino, 1988, pp. 658-661). San Agustín, por su parte, trata la visita de Jesús al hogar de Marta y María en su sermón 104. Allí despliega el siguiente argumento para acabar reivindicando a María quien elige la mejor parte que jamás le será quitada. Las dos hermanas eligen una parte del señor para atender. Cada una atiende a esa parte con la naturaleza que le corresponde a dicha parte por eso María atendía con la contemplación a Dios mismo y Marta atendía activamente. La supremacía de lo abstracto por sobre lo concreto Agustín lo demuestra apelando a que en el plano terrenal operamos con una regla que es que si desaparece la falencia o necesidad de la carne no podemos hablar más de que podamos atender a algo puesto que no existe más, nos es quitado. Tras noblemente saciar la sed del sediento y el hambre del ambiente ya no hay con quien compartir pan y agua. Si está vestido quien estaba en harapos ya no hay desnudez alguna, si no hay riñas ya no hay a quien poner de acuerdo (Sermón 104, Marta y María (Lc 10,38-42), Trad. Pío de Luis Vizcaíno), Extraído de https://www.augustinus.it/spagnolo/discorsi/discorso_133_testo.htm Fecha de consulta: 2/2/2019 
alma bien ejercitado y que sabía ordenar la acción, mientras que no dice ello de su hermana María. ${ }^{10}$

A María eran tres cosas las que la motivaban a estar cerca de Jesús: La bondad divina, su inexpresable deseo y el consuelo que tomaba de las palabras de Jesús. Por su parte, a Marta las tres cosas que la motivaban a servir a Jesús era su madurez, la importancia de quien era su huésped y, más importante, su fondo ejercitado al extremo que Eckhart señala como digno de elogio. Eckhart argumenta que Marta efectivamente "ha recibido la satisfacción espiritual que tiene lugar cuando la cima más alta del alma no se inclina por causa de las alegrías y no se ahoga en el bienestar, sino que permanece por encima de ellas" (Eckhart, 1998, p. 103). La "chispita" que se halla en las profundidades del alma sólo puede ejercitarse ejerciendo el abandono espiritual del yo y del mundo, actuando sin preocupaciones ni apego alguno. ${ }^{11}$ Marta tiene ese fondo de su alma bien ejercitado y es con esa preparación espiritual que Marta se dedica a sus muchas y diversas cosas. Mcginn al respecto agrega: "actuar desde un fondo bien ejercitado (wol geubte grunt), como el sermón 86 de Marta en Lucas 10, es vivir y actuar sin por qué (sunder/ane warumbe), el corazón de la ética eckhartiana" (Mcginn, 2001, p. 49). ${ }^{12}$ Eckhart conceptualiza a ese fondo del alma bien ejercitado como una condición para unirse sin intermediarios a Dios. La maravilla de Marta es que ejerce una acción que en apariencia es torpe y superficial, pero Eckhart logra ver en Marta la acción desasida que hace que el fondo de su alma esté recibiendo al Señor en ella. En palabras del Maestro: "estamos situados en el tiempo para que por una acción temporal correcta lleguemos a estar más cerca de Dios y seamos más semejantes a él” (Eckhart, 2013, p. 106). ${ }^{13}$

Una contemplación consagrada a la satisfacción espiritual y la satisfacción o el gozo sólo hace que el ser humano permanezca dentro de sí y no madure espiritualmente. Ese es el caso de María, quien se consagraba al júbilo y su alma se impregnaba de éxtasis y amor. Marta estaba consagrada a múltiples acciones y desviando su atención de la figura de Jesús es la reivindicada por Eckhart, ya que estaba en realidad sustantivamente más unida a la Divinidad gracias a su "des-enfoque" contemplativo. Una vez más se remarca que ese desvío voluntario del apego que renuncia a las cosas es en realidad una marca de una profunda actividad y madurez espiritual. María no se abre a Dios si se consagra al

\footnotetext{
${ }^{10}$ Haas se pronuncia sobre Marta y la "chispita" comentando que Marta "ha recibido la satisfacción espiritual que tiene lugar cuando la cima más alta del alma no se inclina por causa de las alegrías y no se ahoga en el bienestar, sino que permanece por encima de ellas" (Haas, 2002, p. 108).

${ }^{11}$ A dicho concepto Meister Eckhart se refiere como "scintilla" en latín, "vulkenein" en alemán y se ha traducido al español como "chispita" (Haas, 2002).

${ }^{12}$ Linge exclama respecto al concepto de chispita: "esta chispita en las profundidades del alma solo puede ser recuperada por un total abandono de la identidad que provee el mundo de la multiplicidad" (Linge, 1978, p. 478. La traducción es mía).

${ }^{13}$ Sobre este punto crucial de Marta,la acción desasida, Linge afirma: "la pobreza es la línea de demarcación entre la acción llena de uno y dirigida a uno y la acción descargada de uno mismo" (Linge, 1978, p. 481. La traducción es mía).
} 
gozo y a la satisfacción espiritual mientras que Marta por su parte vacía su interior para penetrar en Dios y permitir que Dios penetre en ella.

Cuando Marta asiste a su huésped está siendo un paradigma del camino del desasimiento. Mangin lo ilustra con claridad de la siguiente manera: "La vida virtuosa consiste en practicar exteriormente las obras con una voluntad interior orientada hacia Dios" (Mangin, 2000, p. 321). Esa voluntad del alma es perfecta cuando está totalmente desapropiada de ella misma. María vuelve su voluntad intelectual sobre ella misma y el gozo de las palabras de Jesús, mientras que Marta la desapega y actúa abierta, vaciada y lista para ser instrumento de Dios.

\section{CONCLUSIONES FINALES}

La correcta acción se califica de desasida. Si, como María, a un acto como el estar recostada a los pies de Jesús se lo acompaña con una contemplación que se llena de la dulzura y se emboba con el éxtasis que produce contemplar al Hijo no se está actuando conforme a la doctrina del desasimiento. De ahí que a Eckhart no le importe que Marta sea algo torpe o distraída, ya que lo es solo en apariencia. El vínculo directo con Dios necesita una acción desasida y es por tal motivo que Marta está unida a Dios a través (y no a pesar) de su servicio.

Una Marta dedicada a la acción múltiple pero desasida y una María arrobada mediante una contemplación de Jesús propia de la satisfacción y no del desasimiento componen el antagonismo espiritual que a Eckhart le interesa destacar. El fin de su lectura del evangelio es normativo: hay una espiritualidad digna de ser vivida. La llamada por Mangin (2000, p. 309) "inmadurez espiritual" de María trae a colación la distinción eckhartiana entre una hermana perfecta y otra imperfecta, donde Marta se vuelve paradigma para María.

Eckhart, como se ha visto, reivindica en esas múltiples y varias acciones de Marta. Él se apropia de esas tradicionales desestimaciones a Marta para volverlas parte de su arsenal filosófico y de su argumentación en favor de Marta. Ella puede lograr la unión con Dios gracias a la conjugación que hace de contemplación en su acción. La superioridad espiritual de Marta es superlativa aun dedicándose a acciones domésticas cuando Jesús la visita.

Filippi se pronuncia respecto a la vida activa de Marta al dar cuenta de cómo ella era la hermana que se llevaba la mejor parte:

no necesitaba como María la suspensión de actividades para atender a las palabras de Jesús, sino que su ocupación había dejado de constituir un obstáculo para ella. De eso se trata no de la reclusión y del apartamiento del mundo sino de que el ajetreo de la vida cotidiana pierda 
toda densidad, todo carácter opresor y apremiante. Más aún, cuando el hombre logra el desapego, no sólo respecto de las cosas circundantes, sino de sí mismo, entonces accede al fondo del alma (Filippi, 2003, p. 36)

Sintetiza Filippi en un par de líneas la concepción eckhartiana de espiritualidad encarnada en Marta y su maestría espiritual: "Para eso es preciso ejercitarse intensamente, utilizar en gran medida todas las cosas y abundar en obras. Lo que importa es el espíritu con que se actúa" (Filippi, 2003, p. 76). Una vez más se ve que la manera en que Eckhart aborda la espiritualidad de las hermanas no es optando por la estrategia tradicional de contraponer acción y contemplación para luego priorizar a alguna por sobre otra. Eckhart entiende que lo importante es la acción pero acompañada de un trabajo espiritual que consista en anular toda carga contemplativa de las acciones. Esta pseudo paradoja espiritual que requiere que el trabajo contemplativo sea el de no contemplar atraviesa toda la mística eckhartiana donde el ser humano debe salir de sí mismo pero esa salida la debe efectuar él mismo.

Haas, por su parte, expone razones exegéticas por las cuales la mística se hace presente en el Sermón 86 de Eckhart. Como se ha expuesto, la piedra de toque de la mística eckhartiana es el abandono del yo, la renuncia de uno a uno mismo y el mundo. El desasimiento y la acción desasida es condición para ser uno con Dios. Haas introduce la espiritualidad eckhartiana utilizando una explicación que trata la vida de aquel que quiere llegar a la unión mística como una oscilación entre polaridades positivas y negativas. En apariencia el desasimiento y la renuncia al apego con lo mundano puede concebirse como una serie de exigencias "negativas". Esta negatividad es sólo aparente ya que es gracias a ese trabajo espiritual que llegamos a ser instrumentos de Dios, la más positiva de las posibilidades de vida (Haas, 2002).

Cómo nuestro interior acompaña nuestras acciones es lo relevante para la doctrina del desasimiento. Cómo está dispuesto dicho interior cuando actuamos es lo que nos permitirá vaciarnos y desapegarnos del mundo. Haas atiende a este punto con fineza: "Hay que tener en cuenta que no se está desvalorizando la contemplación en sí, sino que se la relativiza en la medida en que tiene el carácter de una posesión espiritual". (Haas, 2002; 109).

María está perdida en la espiritualidad del éxtasis, ella no está dirigiendo su alma como debe hacerlo para así poder actuar sin porqué y sin apego a las cosas ni a los resultados. Marta practicó el desasimiento, renunció a ella misma y a la alteridad de las cosas, actuó sin porqué, y sin necesidad de tumbarse a sus pies estaba mucho más cercana a Dios que su hermana María. Marta logró el sublime traspaso y culminó este camino 
espiritual de la unión mística, llegó al mejor de los puertos. La madurez espiritual de Marta la llevan a acompasar acción y contemplación. ${ }^{14}$

María es una principiante en lo que a la espiritualidad respecta, ella se ocupaba gustosa del contento de su alma. Ella a los pies de Jesús apegada a Él y dejando que sus palabras penetren en su alma y la llenen hace que su alma no se subsuma en la esencia divina, su alma se queda llena de esa alegría y gozo.

En cuanto al camino espiritual que ha tomado Marta, Mcginn (2001, p. 160) lo reconstruye señalando que ella se ha comprometido con una "mente libre" (vrien geтиete), que vive desde un fondo espléndido (ein herlicher grunt) y encontró lo verdaderamente necesario: encontró a Dios. De acuerdo a la lectura de Mcginn el fin pedagógico del sermón 86 es que quienes oyen la prédica entiendan que una acción procedente de ese "fondo bien ejercitado" es una acción donde Dios y el ser humano son una misma cosa (Mcginn, 2001, p. 161). Marta sabe lo que tiene que hacer para unirse con Dios. La cuestión radica en cómo nos apegamos a la alteridad, cómo actuamos respecto a obtener algún tipo de regocijo. La aprendiza María aún falla en esas cuestiones espirituales.

Se ha visto a la luz de las palabras del Maestro en el sermón y sus pláticas espirituales que es plausible notar que la argumentación en favor de Marta se debe a que ella ya encarnaba la perfección espiritual que requiere la doctrina del desasimiento. Si bien el río de exégesis que corre alrededor de los textos eckhartianos es un río de vertientes diversas, la gran mayoría de los exégetas de Eckhart encuentran que en sus textos hay efectivamente una antropología tal que el Maestro es capaz de valorar positivamente con una gran sofisticación filosófica la vita activa encarnada en Marta. ${ }^{15}$

\section{SOBRE EL AUTOR}

Santiago Poznansky es estudiante avanzado de la carrera Filosofía en la Facultad de Filosofía y Letras (FFyL) de la Universidad de Buenos Aires (UBA). Cursó estudios de Filosofía en la Universidad Complutense de Madrid (UCM) durantenel 2020. Sus áreas de interés son la teoría política clásica y el misticismo medieval. Actualmente es estudiante adscripto a la cátedra de filosofía del derecho de su facultad.

\section{BIBLIOGRAFÍA}

\footnotetext{
${ }^{14}$ La imagen de la navegación y los puertos la utiliza San Agustín en su sermón 104.

${ }^{15}$ El detractor acérrimo de la lectura mística de la obra de Eckhart, Kurt Flasch, se pronuncia explícitamente respecto al sermón 86. Remarca que Eckhart estaba influenciado por éticos de la virtud paganos como Séneca, Aristóteles y que dicha influencia pudo haber devenido en el que el Maestro haya tratado de ver en Marta un tercer modo de vida (superador de la vida activa y la vida contemplativa) pero que no es una prueba necesaria ni suficiente de que la reivindicación sea gracias a la faceta mística que cuantiosos especialistas atribuyen a Eckhart (Flasch, 2016, p. 222).
} 
Albert, K (2012). Meister Eckhart, between mysticism and philosophy, en J. Hackett, $A$ Companion to Meister Eckhart. Brill's Companions to the Christian Tradition, Vol. 36 (pp. 723-726). Boston: Brill.

Duclow, D. (1989). Whose Image Is This? Mystics Quarterly, Vol. 15, No. 1, pp. 29-40.

Eckhart, M. (2013). Tratados y sermones, Buenos Aires: Editorial Las Cuarenta.

Filippi, S. (2010). Gelassenheit: el desapego como forma de vida en la mística eckhartiana, Enfoques, Vol. 22, pp. 63-78.

Filippi, S. (2003). Martin Heidegger y la mística eckhartiana, Rosario: Invenio.

Flasch, K. (2009). Meister Eckhart philosopher of christianity, New Haven: Yale University Press.

Haas, A. (2002). Maestro Eckhart: figura normativa para la vida espiritual, Barcelona: Herder.

Linge, D. (1978). Mysticism, Poverty and Reason in the Thought of Meister Eckhart. Journal of the American Academy of Religion, Vol. 46, No. 4.

Mangin, E. (2000). La figure de Marthe dans le Sermon 86 d'Eckhart. Modèle du véritable détachement et réponse à certaines dérives spirituelles, Estrasburgo: Revue des Sciences Religieuses.

McGinn, B. (2001). The mystical thought of Meister Eckhart, Nueva York: The Crossroad Publishing Company.

Milem, B. (2012). Meister Eckhart's vernacular preaching. J. Hackett, A Companion to Meister Eckhart. Brill's Companions to the Christian Tradition. Boston: Brill.

Radler, C. (2010). In love I am more God: The Centrality of Love in Meister Eckhart's Mysticism, The Journal of Religion, Vol. 90, No. 2, pp. 171-198.

Schurmann, R. (1981). Meister Eckhart's "verbal" understanding of being as a ground for destruction of practical teleology. En W. Kluxen (ed.), Sprache und Erkenntnis im Mittelalter (pp. 803-809) New York: Miscellanea Mediaevalia.

Tobin, F. (1984). Mysticism and Meister Eckhart. Mystics Quarterly, Vol. 10, №1, pp. 17-24.

Tomás de Aquino (1988). Suma de Teología, Madrid: Biblioteca de Autores Cristianos. 